OPEN ACCESS

Edited by: Mats Granlund,

Jönköping University, Sweden

Reviewed by:

Lan Yang,

The Education University of Hong Kong, Hong Kong

Nina Klang,

Uppsala University, Sweden

*Correspondence: Kai Nagase knagase@yamaguchi-pu.ac.jp

Specialty section:

This article was submitted to Special Educational Needs, a section of the journal Frontiers in Education

Received: 09 June 2020 Accepted: 17 September 2020 Published: 06 October 2020

Citation:

Nagase K, Tsunoda K and Fujita K (2020) The Effect of Teachers

Attitudes and Teacher Efficacy for Inclusive Education on Emotional

Distress in Primary School Teachers in Japan. Front. Educ. 5:570988. doi: $10.3389 /$ feduc. 2020.570988

\section{The Effect of Teachers' Attitudes and Teacher Efficacy for Inclusive Education on Emotional Distress in Primary School Teachers in Japan}

\author{
Kai Nagase*, Kenji Tsunoda and Kumi Fujita \\ Faculty of Social Welfare, Yamaguchi Prefectural University, Yamaguchi, Japan
}

The purpose of this study is to examine the relationship between teachers' attitudes toward and teacher efficacy in inclusive education, and the emotional distress in Japan. A survey of 158 primary school teachers in Yamaguchi prefecture, Japan measured the attitudes of regular and special education teachers for inclusive education and teacher efficacy toward inclusive education to assess the impact of these factors on teachers' emotional distress. The results indicated that the teachers' emotional distress was significantly and negatively correlated with attitudes toward integrated classroom management and perceived ability to teach students with disabilities. Furthermore, teachers' emotional distress was significantly and negatively correlated with high teacher efficacy in inclusive instruction, collaboration, and managing behavior. A regression analysis was performed which further confirmed that efficacy in collaboration and managing behavior were unique predictors of emotional distress in primary school teachers. These findings can provide useful insights into the issue of emotional distress in primary school teachers.

Keywords: primary school teachers, inclusive education, attitude, teachers' efficacy, emotional distress

\section{INTRODUCTION}

Recently, the issue of the emotional distress of primary school teachers has been gaining attention in Japan (Nishida and Otomo, 2010; Takahara, 2015; Hasegawa-Ohira et al., 2016). For example, a study by Hasegawa-Ohira et al. (2016) examined the emotional distress of both primary school and junior high school teachers by using the General Health Questionnaire-28 (GHQ-28), developed by Goldberg (1978) and since translated into 38 languages. Developed as a screening tool to detect those likely to have or to be at risk of developing psychiatric disorders, it uses a 28-item measure of emotional distress (Stering, 2011). Their results clearly showed that many teachers suffered from emotional distress. In this regard, Nishida and Otomo (2010) pointed out that primary school teachers were more likely to experience significant emotional distress as a result of being surrounded by various stressors and also because the teaching profession is very socially demanding. Evidence like this underscores the importance and the necessity of considering the factors affecting the emotional distress of primary school teachers. 
It has been pointed out that one of the effects of inclusive education in primary schools may be to affect the emotional distress of teachers (Talmor et al., 2005; Mori and Tanaka, 2011, 2012). Inclusive education has become the mainstream in global education policy since the Salamanca Statement on Principles, Policy, and Practice in Special Needs Education. Adopted by 92 countries (including Japan) at the World Conference on Special Needs Education: Access and Quality in 1994, this statement reaffirmed the principle 'Education for All' and recognized the necessity and urgency of providing education for children, youth, and adults with special educational needs within the regular education system (UNESCO, 1994). Inclusive education is a system whereby students with or without disabilities can learn together. For this to be possible, the opportunity to receive primary and secondary education in areas where students with disabilities reside must be provided (Takahashi and Matsuzaki, 2014). In addition, the opportunity to receive reasonable accommodation that students with disabilities need to access inclusive education must be made available (Takahashi and Matsuzaki, 2014). In Japan, inclusive education is being promoted through 'Special Needs Education', which is the Japanese special education system. The specific aim of 'Special Needs Education' is to build a society where all individuals, regardless of having disabilities or not, are respected, and those with disabilities are able to participate fully in society (Nakamura and Oka, 2007; Song, 2016). The 'Special Needs Education' system focuses on 'needs' rather than 'disabilities' so that all students who are experiencing difficulties, such as those with developmental disorders, can receive the appropriate educational support (Murata and Yamaguchi, 2010; Song, 2016).

Mori and Tanaka (2011) examined the present condition of emotional distress in teachers teaching students with special educational needs in the 'Special Needs Education' system. Their analysis of the results of a GHQ-28 survey of teachers teaching students with special educational needs shows that approximately $70 \%$ of them had some emotional distress. This result suggests that teaching students with disabilities and being engaged in inclusive education in primary schools may affect the emotional distress of teachers. It is postulated that one reason for this is the diverse needs of students. For instance, Beppu (2013) indicated that teachers suffered from emotional distress arising from the fact that they were not able to build relationships while teaching students with special educational needs due to their diverse educational needs. In addition, Mori and Tanaka (2011) pointed out that a high level of professionalism is required in teachers who teach students with disabilities. This professionalism encompasses high levels of appropriate teaching and support skill based on individual needs, along with cooperation between schools and welfare, medical, health, and labor organizations. Mori and Tanaka (2011) also pointed out that most of the teachers teaching students with disabilities had emotional distress because of these high levels of professionalism expected from them. Thus, it is important to consider the relationship between professionalism and emotional distress in elementary school teachers who are engaged in the education of students with disabilities in more detail.
Previous studies focused on teachers' attitudes toward and teacher efficacy in inclusive education as one of the aspects of professionalism required of teachers teaching students with disabilities in an inclusive education setting (Song, 2016). In this study, our first step is to describe teachers' attitudes toward inclusive education. Attitudes are conceptualized as relatively stable constructs comprising cognitive, affective, and behavioral components (Bizer et al., 2003). Teachers' attitudes toward inclusive education are often based on practical concerns about how inclusive education can be implemented, rather than being grounded in any particular ideology (Vaz et al., 2015). Antonak and Larrivee (1995) developed the Opinions Relative to Integration of Students with Disabilities scale (ORI) and identified four factors on the scale as follows: benefits of integration (BF), integrated classroom management (ICM), perceived ability to teach students with disabilities (PATSD), and special versus integrated general education (SIGE). Moreover, Navarro-Mateu et al. (2019) analyzed the predictive power of sociodemographic variables, empathy (cognitive and emotional), and social dominance orientation (social dominance and opposition to equality) on teachers' attitudes, sentiments, and concerns about inclusion. They also showed that social dominance is negatively related to attitudes and positively related to sentiments and concerns.

Previous studies have tended to focus on whether teachers have a positive perception of these components of attitudes toward inclusive education. For example, Avramidis et al. (2000) examined the relationship between attitudes toward inclusive education and experience of inclusion in 81 primary and secondary teachers; their results showed that teachers who had been implementing inclusive programs, and therefore had active experience of inclusion, possessed more positive attitudes. Additionally, Praisner (2003) examined the relationship between attitudes toward inclusive education and experiences with students with disabilities in 405 primary school principals. Praisner (2003) revealed that positive attitudes toward inclusive education in primary school principals were associated with positive experiences with students with disabilities. These studies suggest the possibility that positive attitudes toward inclusive education are considered to reduce teachers' emotional distress. This may be because as Hopman et al. (2018) showed, a good relationship between teachers and students with disabilities moderates teachers' emotional exhaustion. In other words, teachers with positive attitudes toward inclusive education can build a good relationship with students; hence, they may be less likely to face emotional distress.

Whereas, De Boer et al. (2011) reviewed 26 previous research studies about primary school teachers' attitudes toward inclusive education and their analysis indicated that the majority of teachers held neutral or negative attitudes toward the inclusion of pupils with special needs in regular primary education. In addition, Haq and Mundia (2012) showed that preservice teachers held negative attitudes toward including students with high support needs such as those with sensory and mentally challenging behaviors, and multiple disabilities in the classroom in particular. Therefore, based on the possibility that positive attitudes toward inclusive education are considered to reduce 
teachers' emotional distress, it may be considered that many teachers have emotional distress due to their negative attitudes toward inclusive education. Based on these previous research studies, it is necessary to examine the relationship between attitudes toward inclusive education and emotional distress in primary school teachers.

Our next step is to describe teacher efficacy in regard to inclusive education. Teacher efficacy is defined as a teacher's beliefs or perceptions about his or her ability to teach students with different kinds of needs and bring about desired changes in student achievement (Tschannen-Moran et al., 1998; Minghul et al., 2018). Previous studies have indicated that teacher efficacy is one of the most pervasive factors that potentially distinguishes teachers who teach effectively from those who usually struggle in teaching students (Tschannen-Moran and Hoy, 2001; Minghul et al., 2018). In addition, Skaalvik and Skaalvik (2010) found that high levels of teacher efficacy reduced emotional exhaustion and depersonalization, which are often cited as symptoms of burnout (Maslach et al., 1996). These studies suggested that high levels of teacher efficacy are considered as reducing primary school teachers' emotional distress, and that the reverse is also true: low teacher efficacy can lead to emotional distress. While research studies on teacher efficacy in general have been accumulating for a while, studies of teacher efficacy specifically for inclusive education have recently been coming to the fore. Sharma et al. (2012) developed the Teacher Efficacy for Inclusive Practice scale (TEIP), which is an instrument designed to measure perceived teacher efficacy in teaching in inclusive classrooms. In the TEIP, three specific factors were identified: efficacy in using inclusive instructions (EII), efficacy in collaboration (EC), and efficacy in managing behavior (EMB). This factor structure in the TEIP has been confirmed in an additional study (Park et al., 2016). The ability to employ and utilize inclusive instruments, and the abilities for collaboration and managing behavior are essential abilities in inclusive education in Japan (Okamoto, 2014; Utsumi and Ando, 2017). Previous studies showed the relationship between teacher efficacy for inclusive education and teaching students with special educational needs. For instance, Chao et al. (2018) examined the relationship between inclusive teaching tasks and teacher efficacy, and showed some tasks which were specifically required in inclusive education, such as collaboration tasks, which represented high teacher efficacy. This suggests that teacher efficacy for inclusive education is linked to the effective teaching of students with disabilities in an inclusive classroom. Previous studies have showed that effective teaching of students with disabilities reduces the emotional distress of teachers, avoiding situations such as that of a burnout (Sakamoto and Ichikado, 2013). In fact, Malinen and Savolainen (2016) showed teacher efficacy in behavior management affected both job satisfaction and burnout by using a longitudinalsectional design. Based on these previous research studies, high teacher efficacy toward inclusive education would reduce primary school teachers' emotional distress in an inclusive classroom environment because it would enable the effective teaching of students with disabilities.

In addition, previous studies have shown that attitudes toward inclusive education are closely associated with teacher efficacy for inclusive education (Malinen et al., 2012; Sharma et al., 2014; Yada and Savolainen, 2017; Özokcu, 2018). Malinen et al. (2012) examined the relationship between self-efficacy for inclusive practices, respondents' background factors, and attitude toward inclusive education. Their results showed that high efficacy in using inclusive instruction, collaboration, and managing behavior was associated with positive sentiments, attitudes, and concern about inclusive education. Özokcu (2018) examined the relationship between attitudes toward inclusive education and teacher efficacy for inclusive education among teachers in Turkey, and showed that teacher attitudes toward inclusive education were positively associated with teacher efficacy for inclusive practices. Yada and Savolainen (2017) also examined this relationship in primary and secondary education teachers in Japan. They also found that high teacher efficacy for inclusive education regarding managing behavior and collaboration was related to overall positive attitudes toward inclusive education. Some previous studies about teacher efficacy have showed that teacher efficacy is an independent predictor of emotional distress in teachers (Skaalvik and Skaalvik, 2014, 2016). Hence, based on the previous studies cited in this section, attitudes and teacher efficacy for inclusive education may be considered to be linked to each other, and can be said to affect teachers' emotional distress.

So far, we have reviewed previous studies on attitudes and teacher efficacy for inclusive education. Previous studies pointed out that the two areas of attitudes and teacher efficacy for inclusive education are related to each other, and the possibility that the two areas of attitudes and teacher efficacy for inclusive education are associated with teachers' emotional distress. However, there have been no previous studies directly examining the relationship between teachers' attitudes and teacher efficacy for inclusive education, and their emotional distress in Japan. Previous studies have used General Health Questionnaires (GHQ) to measure the emotional distress of adults in Japan (e.g., Higuchi et al., 2016). The GHQ was developed by Goldberg and Hillier in 1979 as a screening instrument for identifying psychological distress among adults in primary care settings, and evaluating anxiety and depression symptoms in individuals without psychiatric disorders (Goldberg and Hillier, 1979). Several short versions of the GHQ have been created, but the 12-item GHQ (GHQ-12) is known to have the least psychological burden on participants. Moreover, the GHQ-12 has been well-validated for general Japanese adult population. Thus, it is a suitable scale to measure emotional distress in primary school teachers in this study. The purpose of this study is therefore to examine this relationship and to interpret the significance of the results in terms of their implications for the emotional distress of teachers who are involved in the implementation of inclusive education in Japan. Teachers' attitudes and teacher efficacy for inclusive education can be recaptured from a new perspective by clarifying this relationship. Previous studies have examined the factors that influence teachers' attitudes and teacher efficacy for inclusive education (Peebles and Mendaglio, 2014; Sokal and Sharma, 2014; Vaz et al., 2015), but not how teachers' attitudes and teacher efficacy for inclusive education affect primary school teachers. Hence, this study is expected to deepen the 
understanding of teachers' attitudes and teacher efficacy for inclusive education.

\section{MATERIALS AND METHODS}

\section{Participants and Procedure}

This study was conducted in the Yamaguchi prefecture in Honshu, Japan. We mailed the questionnaire to 289 elementary schools in Yamaguchi prefecture, and valid questionnaires were returned by 158 primary school teachers (56 males and 102 females) whose mean age was $40.54(S D=11.99)$. The mean value of their years of service as teachers was $16.20(S D=12.10)$, and $20.25 \%$ of the participants $(N=32)$ held the special teacher licenses required for teaching in special education schools. All participants were Japanese. The demographic characteristics of the participants are further illustrated in Table $\mathbf{1}$.

\section{Questionnaires}

\section{Brief Demographic Information}

Demographic information of the participants was obtained by asking questions about their age, gender, years of service as a teacher, whether they possessed a teacher's license for special education schools, and the number of students in their class.

\section{The Opinions Relative to Integration of Students With Disabilities Scale (ORI)}

Attitude toward inclusive education was measured by the Opinions Relative to Integration of Students with Disabilities scale (ORI). As mentioned earlier, the ORI is a scale developed by Antonak and Larrivee (1995), and is appropriate for this study because it measures the attitudes of regular and special education teachers toward inclusion. This scale measures the attitudes of regular and special education teachers toward inclusive education, and has four subscales. The ORI contains 25 positively

TABLE 1 | Demographic characteristics of the participants.

\begin{tabular}{|c|c|c|c|}
\hline & Female & Male & Total \\
\hline Number & 102 & 56 & 158 \\
\hline Mean age $(S D)$ & $41.24(16.45)$ & $39.30(11.35)$ & 40.54 (11.99) \\
\hline $\begin{array}{l}\text { Mean years of service as } \\
\text { teachers }(S D)\end{array}$ & 16.45 (12.33) & $15.72(11.76)$ & $16.20(12.10)$ \\
\hline $\begin{array}{l}\text { Number of participants who have } \\
\text { a teacher's license for special } \\
\text { education schools (proportion) }\end{array}$ & $26(25.5 \%)$ & $6(10.7 \%)$ & 32 (20.3\%) \\
\hline $\begin{array}{l}\text { Median number of students in } \\
\text { their class }\end{array}$ & 26 & 23 & 25 \\
\hline $\begin{array}{l}\text { Median number of students with } \\
\text { a disability in their class }\end{array}$ & 1 & 1 & 1 \\
\hline \multicolumn{4}{|l|}{ Class grade } \\
\hline Lower grade & 39 & 9 & 48 \\
\hline Middle grade & 39 & 22 & 61 \\
\hline Higher grade & 23 & 21 & 44 \\
\hline $\begin{array}{l}\text { Lower, middle, and higher grade } \\
\text { are mixed }\end{array}$ & 0 & 3 & 3 \\
\hline Unanswered & 1 & 1 & 2 \\
\hline
\end{tabular}

and negatively worded statement options rated on a 6-point continuum, eliminating the non-informative middle value on the original response continuum. An example of an item in this scale is: "The integration of special needs students can be beneficial for regular students." The available responses to the statements were composed of the following: -3 , 'I disagree very much'; -2 , 'I disagree pretty much'; -1, 'I disagree a little'; +1, 'I agree a little'; +2 , 'I agree pretty much'; and +3 , 'I agree very much.' The responses to the 25 items were scored in the direction of positive attitude and then summed. A constant of 90 was then added to this total to eliminate negative scores, meaning that potential scores could range from 0 to 180 . As also mentioned earlier, four specific factors were identified in the ORI scale: benefits of integration (BF), integrated classroom management (ICM), perceived ability to teach students with disabilities (PATSD), and special versus integrated general education (SIGE). An example of an item in BF is: "The integration of students with disabilities can be beneficial for students without disabilities." An example of an item in ICM is: "Students with disabilities are likely to create confusion in general classroom." An example of an item in PATSD is: "General classroom teachers have the ability necessary to work with students with disabilities." An example of an item in SIGE is: "Students with disabilities can be best served in general classrooms." A significant number of highly regarded previous studies have examined attitudes toward inclusive education using the ORI (e.g., Antonak and Larrivee, 1995; Ismail et al., 2016; Vaz et al., 2015). In the current study, the Cronbach's alpha coefficient for the ORI was 0.79. The Cronbach's alphas for the ORI subscale also were $0.60,0.72,0.54,0.44$ for BF, ICM, PATSD, SIGE.

\section{The Teacher Efficacy for Inclusive Practice (TEIP) Scale}

Teacher efficacy for inclusive education was measured by the Teacher Efficacy for Inclusive Practice (TEIP) scale. The TEIP measures primary school teachers' teaching efficacy beliefs for inclusive practice and the details of the scale development procedures along with its validity and reliability are described in Sharma et al. (2012). The scale consists of 18 items scored on a 6 -point Likert scale ( 1 = strongly disagree, 2 = disagree, 3 = disagree somewhat, $4=$ agree somewhat, $5=$ agree, and 6 = strongly agree). The TEIP yields a total score that is obtained by adding the value of the responses to each item. An example of an item in this scale is: "I am able to provide an alternate explanation or example when students are confused." The value of the total score can therefore range from a minimum of 18 to a maximum of 108. Higher scores on the TEIP suggest that a respondent is relatively more efficacious for teaching students with diverse learning needs in an inclusive classroom (Sharma et al., 2014). As mentioned earlier, three specific factors were identified in the TEIP: efficacy in using inclusive instructions (EII), efficacy in collaboration (EC), and efficacy in managing behavior (EMB). An example of an item in EII is: "I can use a variety of assessment strategies (for example, portfolio assessment, modified tests, performance-based assessment, etc.)." An example of an item in EC is: "I can assist families in helping their children do well in school." An example of an item in EMB is: "I am confident in my ability to prevent disruptive behavior in the classroom before 
it occurs." As is the case with the ORI, a significant number of previous highly regarded studies have examined attitudes toward inclusive education using the TEIP (e.g., Sharma et al., 2012, 2014; Park et al., 2016; Alnahdi and Hui, 2019). In the current study, the Cronbach's alpha coefficient for the TEIP was 0.93. The Cronbach's alphas for the TEIP subscales were 0.82, 0.91, and 0.82 , for EII, EC, and EMB, respectively.

\section{The General Health Questionnaire-12 (GHQ-12)}

Emotional distress of participants was measured by the 12-item General Health Questionnaires (GHQ-12). The GHQ-12 is a widely used instrument which has been translated into more than 30 languages throughout the world and its validity and reliability has been established using Japanese adults (Doi and Minowa, 2003). It is a self-administered screening questionnaire and is used to detect the incidence of minor psychiatric disorders among the general population. In particular, it is intended to evaluate respondents' general emotional distress over the 4 weeks preceding the administering of the questionnaire, and the scale items ask about levels of happiness, depression, anxiety, and sleep disturbance (Doi and Minowa, 2003). Each item is rated on a four-point scale (less than usual, no more than usual, rather more than usual, or much more than usual) and depending on the scoring method selected, the maximum total score can be either 12 or 36 . The most common scoring methods are bimodal (0-0-1-1) and Likert scoring (0-1-2-3). Since the latter produces a more acceptable distribution of scores for parametric analysis (Salama-Younes et al., 2009), each item was rated on a 4 -point Likert scale from 0 to 3 in response to whether the respondents had experienced each symptom over the 4 weeks prior to completing the questionnaire. Therefore, Likert scoring was adopted as a scoring method in this study. In the current study, the Cronbach's alpha coefficient for the GHQ-12 was 0.99.

\section{Translation of Questionnaire Components}

The ORI and the TEIP sections of the questionnaire were originally written in English. For our study, they were translated into Japanese and the content and quality of that translation was checked by the authors, whose native language is Japanese. The authors are also fluent in English and are quite familiar with the specific details of the 'Special Needs Education' system and the state of inclusive education in Japan. Finally, the translated version of the instrument was proofread by teachers with experience of teaching in Japanese primary schools and corrections were agreed upon by all the authors to ensure maximum similarity with the original questionnaires.

\section{Data Analysis}

The first step was to calculate Pearson's correlations between the scores on the four ORI subscales, the scores on the three subscales of the TEIP, and the GHQ-12 score to examine the relationships between attitudes and teacher efficacy for inclusive education and the emotional distress status of primary school teachers in Japan. Then, a multiple linear regression analysis using the forward-backward stepwise selection method was performed containing the subscales of the ORI and the TEIP, which showed a significant correlation with the GHQ-12 score as explanatory variables, and the GHQ-12 score as the outcome variable to examine which aspects of attitudes and teacher efficacy for inclusive education influence emotional distress in primary school teachers in Japan. Statistical Package for the Social Sciences (SPSS) Statistics 23.0 (IBM Corp., Armonk, NY, United States) was used for all analyses.

\section{Ethics Statement}

The study protocol was designed in accordance with the tenets of the World Medical Association (2000). All participants were informed that their privacy and responses would be strictly protected. Furthermore, they were informed that participation was not mandatory, that they could withdraw at any time, and that the data obtained would not be used outside of this study. It was stated on the questionnaire's face sheet that participants need not return the questionnaire if they did not agree to participate in the study. It was therefore considered that returning the questionnaire constituted consent to participate in the study.

\section{RESULTS}

\section{Descriptive Statistics and Correlational Analysis of the ORI, TEIP, and GHQ-12 Scores}

Table 2 presents the descriptive statistics for the ORI, TEIP, and GHQ-12 scores.

The Pearson's correlations between the ORI subscales, the TEIP subscales, and the GHQ-12 are provided in Table 3. First, the correlation between the ORI subscales is described. The scores of the BF subscale of the ORI were positively and lowly correlated with the ICM subscale scores $(r=0.35$, $p<0.01)$ and SIGE subscale scores $(r=0.25, p<0.01)$ significantly. Thus, the participants who reported having positive attitudes toward benefits of integration also reported positive

TABLE 2 | Descriptive statistics in the scores of the ORI, TEIP, and GHQ-12.

\begin{tabular}{lcccc}
\hline & Mean scores & SD & Min & Max \\
\hline The ORI & 81.98 & 13.65 & 43 & 121 \\
Benefits of integration (BF) & 34.16 & 4.99 & 21 & 44 \\
Integrated classroom management (ICM) & 31.72 & 8.56 & 12 & 56 \\
Perceived ability to teach students with & 6.31 & 2.57 & 0 & 12 \\
disabilities (PATSD) & & & & \\
Special versus integrated general education & 9.56 & 3.33 & 2 & 20 \\
(SIGE) & & & & \\
The TEIP & 64.54 & 10.69 & 34 & 91 \\
Efficacy in using inclusive instructions (EII) & 20.50 & 3.89 & 10 & 29 \\
Efficacy in collaboration (EC) & 22.15 & 4.59 & 9 & 34 \\
Efficacy in managing behavior (EMB) & 21.89 & 3.75 & 12 & 31 \\
GHQ-12 & 13.44 & 4.49 & 0 & 27 \\
\hline
\end{tabular}

ORI, opinions relative to integration of students with disabilities scale; TEIP, teacher efficacy for inclusive practice scale; GHQ-12, The General Health Questionnaire12; SD, standard deviation; Min, minimum values; Max, maximum values. $n=158$. 
TABLE 3 | Correlations between the scores on the four ORI subscales, the three TEIP subscales, and the GHQ-12 score.

\begin{tabular}{|c|c|c|c|c|c|c|c|c|}
\hline & 1 & 2 & 3 & 4 & 5 & 6 & 7 & 8 \\
\hline (1) Benefits of integration (BF) & & $0.35^{\star \star}$ & 0.09 & $0.25^{\star \star}$ & -0.06 & -0.08 & -0.03 & -0.02 \\
\hline (2) Integrated classroom management (ICM) & & & 0.14 & $0.40^{\star \star}$ & $0.18^{*}$ & 0.11 & 0.15 & $-0.18^{\star}$ \\
\hline (3) Perceived ability to teach students with disabilities (PATSD) & & & & 0.14 & $0.31^{\star \star}$ & $0.23^{\star \star}$ & $0.27^{\star *}$ & $-0.19^{*}$ \\
\hline (4) Special versus integrated general education (SIGE) & & & & & $0.19^{*}$ & 0.09 & $0.18^{*}$ & -0.09 \\
\hline (5) Efficacy in using inclusive instructions (EII) & & & & & & $0.61^{\star \star}$ & $0.70^{\star \star}$ & $-0.38^{\star \star}$ \\
\hline (6) Efficacy in collaboration (EC) & & & & & & & $0.64^{\star \star}$ & $-0.40^{\star \star}$ \\
\hline (7) Efficacy in managing behavior (EMB) & & & & & & & & $-0.44^{\star \star}$ \\
\hline (8) GHQ-12 & & & & & & & & \\
\hline
\end{tabular}

ORI, opinions relative to integration of students with disabilities scale; TEIP, teacher efficacy for inclusive practice scale; GHQ-12, The General Health Questionnaire-12. $n=156$.

${ }^{*} p<0.05$.

${ }^{* *} p<0.01$.

attitudes to integrated classroom management, and special versus integrated general education. The ICM subscale scores were positively and moderately correlated with SIGE subscale scores $(r=0.40, p<0.01)$ significantly. This indicates that the participants who reported positive attitudes to integrated classroom management also reported positive attitudes to special versus integrated general education. However, there were no significant correlations between PATSD and BF subscale scores $(r=0.09, n . s)$, ICM $(r=0.14, n . s)$, and $(r=0.14, n . s)$.

Second, the correlation between the TEIP subscales is described. The scores of the EII subscale of the TEIP were positively and moderately correlated with the EC scores $(r=0.61$, $p<0.01)$, and strongly correlated with EMB scores $(r=0.70$, $p<0.01)$ significantly. Thus, the participants who reported higher teacher efficacy in using inclusive instructions also reported higher teacher efficacy in collaboration and managing behavior than the other participants. The EC scores were positively and moderately correlated with the EMB scores ( $r=0.64, p<0.01)$ significantly, indicating that the participants who reported higher teacher efficacy in collaboration also reported higher teacher efficacy in managing behavior than the other participants.

Third, the correlation between the ORI subscales and the TEIP subscales is described. The scores of the ICM subscale of the ORI were positively and lowly correlated with the scores of the EII subscales of the TEIP $(r=0.18, p<0.05)$ significantly. Thus, the participants who reported positive attitudes to integrated classroom management also rated higher teacher efficacy in using inclusive instruction than the other participants. The scores of the PATSD subscale of the ORI were positively and moderately correlated with the EII scores $(r=0.31, p<0.01)$, and lowly correlated with EC scores $(r=0.23, p<0.01)$, and EMB scores $(r=0.27, p<0.01)$ significantly. Thus, the participants who reported positive attitudes toward perceived ability to teach students with disabilities also reported higher teacher efficacy in using inclusive instruction, collaboration, and managing behavior than the other participants. The scores of the SIGE subscale of the ORI were positively and lowly correlated with the EII scores $(r=0.19, p<0.05)$ and the EMB scores $(r=0.18, p<0.05)$ significantly. Thus, the participants who reported positive attitudes to special versus integrated general education also reported higher teacher efficacy in using inclusive instruction and managing behavior than the other participants. However, there were no significant correlations between: BF and EII $(r=-0.06, n . s)$, EC $(r=-0.08, n . s)$, EMB $(r=-0.03, n . s)$; ICM and EC $(r=0.11, n . s)$ and $\operatorname{EMB}(r=0.15, n . s)$; and SIGE and $\mathrm{EC}(r=0.09, n . s)$.

Finally, the correlation between the GHQ-12, and the ORI and TEIP subscales is described. The GHQ-12 scores were negatively and lowly correlated with the scores of the ICM $(r=-0.18$, $p<0.05)$, PATSD $(r=-0.19, p<0.05)$, EII $(r=-0.38, p<0.01)$, and EC $(r=-0.40, p<0.01)$, and moderately correlated with EMB $(r=-0.44, p<0.01)$ significantly. Thus, the participants who reported higher emotional distress also reported positive attitudes to integrated classroom management and perceived ability to teach students with disabilities as well as higher teacher efficacy in using inclusive instruction, collaboration, and managing behavior than the other participants. There were no significant correlations between GHQ-12 and BF scores $(r=-0.02, \mathrm{n} . \mathrm{s})$ and SIGE $(r=-0.07, \mathrm{n} . \mathrm{s})$.

\section{Stepwise Multiple Linear Regression Analysis}

Stepwise multiple linear regression analysis was performed using ICM, PATSD, EII, EC, and EMB as explanatory variables to examine which aspect of attitudes and teacher efficacy for inclusive education influences emotional distress in primary school teachers in Japan. The variance inflation factors (VIFs) of the variables were examined to determine if multicollinearity was an issue. Table 4 shows the results of the regression analysis. Results of regression analysis adopted a model in which the EC subscale and the EMB subscale influenced emotional distress as measured by the GHQ-12. The coefficient of determination of the model was significant $\left[R^{2}=0.21, F(2,144)=19.27, p<0.01\right]$. The predictors of the model accounted for $21 \%$ variation in emotional distress. Both the EC subscale $(\beta=-0.22, p<0.05)$ and the EMB subscale $(\beta=-0.29, p<0.01)$ of the TEIP were independent and significant predictors of GHQ-12. In addition, the VIFs of EC and EMB, adopted as independent predictors of the model, were both 1.69 , thus satisfying the criterion for absence of multicollinearity (less than 2.00). 
TABLE 4 | Stepwise multiple regression analysis: the scores on the four ORI subscales and the three TEIP subscales as predictors of GHQ-12.

\begin{tabular}{lcccr}
\hline & \multicolumn{5}{c}{ GHQ-12 } \\
\cline { 2 - 5 } & $\boldsymbol{\beta}$ & $\boldsymbol{t}$ & $\boldsymbol{p}$ & VIF \\
\hline $\mathrm{EC}$ & -0.22 & -2.26 & $0.026^{\star}$ & 1.69 \\
$\mathrm{EMB}$ & -0.29 & -3.02 & $0.003^{\star \star}$ & 1.69 \\
ElI $^{\dagger}$ & -0.16 & -1.46 & 0.15 & 2.22 \\
ICM $^{\dagger}$ & -0.12 & -1.61 & 0.11 & 1.01 \\
PATSD $^{\dagger}$ & -0.08 & -1.06 & 0.29 & 1.09 \\
\hline
\end{tabular}

GHQ-12: $R^{2}=0.21, F(2,144)=19.27, p<0.01 ; \beta$, standardized beta coefficients; VIF, variance inflation factor.

${ }^{\dagger}$ Ell, ICM, and PATSD are variables that were not adopted in the model, and each value in the table is the value when inputted.

$* * p<0.01$.

$* p<0.05$.

\section{DISCUSSION}

This study examined the effect of teacher attitudes and teacher efficacy for inclusive education on the emotional distress of primary school teachers in Japan. Before discussing the results of the actual analysis of these effects, the correlation between the attitudes and teacher efficacy for inclusive education need to be discussed with reference to previous studies. The results of this study showed that the scores of the EII subscales of the TEIP were significantly and positively correlated with the scores for ICM, PATSD, and SIGE. Among them, EII scores had a low correlation with the scores for ICM and SIGE, and a moderate correlation with scores for PATSD. These results suggest that high efficacy in the use of inclusive instructions was associated with positive attitudes toward inclusive classroom management, perceived ability to teach students with disabilities, and special versus inclusive general education. In particular, PATSD showed a stronger association with EII than the other subscales of the ORI. These results are similar to the results of previous studies which showed that high efficacy in using inclusive instructions was associated with positive sentiments, attitudes, and concern about inclusive education (Özokcu, 2018). As mentioned above, Sharma et al. (2012) showed that EII consisted of items which related to a participant's perceptions of their teaching efficacy in using inclusive instructions, such as "I can use a variety of assessment strategies (e.g., portfolio assessment, modified tests, performance-based assessment, etc.)". On the other hand, Antonak and Larrivee (1995) described ICM as consisting of items which were concerned with the behavior of the students in an integrated classroom and the classroom management procedures that integration may require, such as "Students with disabilities are likely to create confusion in the general classroom". PATSD consisted of items which represented cognition of the ability in general classroom teachers to teach students with disabilities, such as "General classroom teachers have the ability necessary to work with students with disabilities," while SIGE consisted of items which represented a dichotomous view of the provision of education for students with disabilities, such as "Students with disabilities can be best served in general classrooms." It is considered that teachers with high efficacy in the use of inclusive instructions have the required teaching and instruction skills for students with disabilities (TschannenMoran and Hoy, 2001). In Japan, education about the appropriate teaching and instruction skills required for various educational needs has been provided to pre-service teachers since the initial implementation of the 'Special Needs Education' system (Kawai and Fujii, 2012). Based on this, primary school teachers in this study who display high levels of efficacy in the use of inclusive instruction were considered to have a positive attitude toward perceived ability to teach students with disabilities because they have had the necessary and appropriate education about teaching and instruction skills in the course of becoming primary school teachers. This was reflected in the findings of our study in which EII showed a stronger association with PATSD than the other subscales of the ORI. Participants who display high levels of efficacy in the use of inclusive instruction were also considered to have a positive attitude toward inclusive classroom management and special versus inclusive general education because they would be able to teach students with disabilities well in general classrooms for education about the appropriate teaching and instruction skills required for various educational needs.

The results of this study showed that the scores on the EC subscales of the TEIP were positively and lowly correlated with the PATSD scores significantly. This result suggests that high efficacy in collaboration is associated with positive attitudes toward the perceived ability to teach students with disabilities. This result is similar to the results of previous studies which showed high efficacy in collaboration was associated with positive sentiments, attitudes, and concern about inclusive education (Malinen et al., 2012). EC relates to an individual's perceptions of teacher efficacy in working with parents and other professionals (Sharma et al., 2012). Sharma et al. (2012) described EC as consisting of items, such as "I am able to work jointly with other professionals and staff (e.g., aides, other teachers) to teach students with disabilities in the classroom." EC is different from EII and EMB in that it includes items related to efficacy in working with parents and other professionals, while EII includes items related to efficacy in using inclusive instruction, and EMB includes items related to efficacy in dealing with disruptive behaviors of students with disabilities (Sharma et al., 2012). It is necessary for primary school teachers to collaborate with parents and other professionals in teaching students with disabilities in a general classroom because they need to adequately support students with various educational needs (Okamoto, 2014). In Japan, education about collaboration with parents and other professionals has also been provided to pre-service teachers since the 'Special Needs Education' system began (Kawai and Fujii, 2012). Primary school teachers in this study who have high efficacy in collaboration were considered to have a positive attitude toward the perceived ability to teach students with disabilities because they have received the necessary and appropriate education about collaboration with parents and other professionals in the course of their training to become primary school teachers.

The results of this study show that the scores of the EMB subscales of the TEIP were positively and lowly correlated with the scores of PATSD and SIGE significantly. This result suggests that high efficacy in managing behavior was associated with positive attitudes toward the perceived ability to teach students with disabilities and special versus inclusive general education. 
This result is similar to the results of previous studies which showed high efficacy in collaboration was associated with positive sentiments, attitudes, and concern about inclusive education (Özokcu, 2018). Sharma et al. (2012) described EMB as consisting of items which related to self-perceptions of teaching efficacy in dealing with disruptive behaviors, such as "I am confident in my ability to prevent disruptive behavior in the classroom before it occurs." As can be seen from the results of this study, the concept of EMB is strongly correlated with EII. In other words, it is considered that primary school teachers manage disruptive behavior in students with disabilities by using inclusive instruction. Therefore, primary school teachers in this study who have high efficacy in managing behavior were considered as having a positive attitude toward perceived ability to teach students with disabilities because they have received the necessary and appropriate education about teaching and instruction skills in the course of becoming primary school teachers. They were also considered to have a positive attitude toward special versus inclusive general education because they would be able to manage disruptive behavior in students with disabilities well in a general classroom.

So far, we have discussed the correlation between attitudes toward inclusive education and teachers' efficacy for inclusive education. In this paragraph, we discuss the effect of teachers' attitudes and teacher efficacy for inclusive education on emotional distress of primary school teachers. The results of this study showed that the GHQ-12 scores were negatively and lowly correlated with the IMC and PATSD scores of ORI, and negatively and moderately correlated with the EII, EC, and EMB scores of TEIP significantly. These results show that positive attitudes toward inclusive classroom management and the perceived ability to teach students with disabilities, along with a high efficacy in using inclusive instructions, collaboration, and managing behavior is associated with emotional distress. As mentioned above, previous studies have showed that teacher efficacy is associated with emotional distress in teachers. The results of this study extend this finding to the field of inclusive education, by providing evidence that both teacher efficacy and teachers' attitude toward inclusive education are associated with emotional distress. In addition, the regression analysis further confirmed that EC scores and EMB scores were unique predictors of GHQ-12 scores in primary school teachers in Japan. In particular, the results of the regression analysis showed that teachers with high efficacy in collaboration and managing behavior had less emotional distress. These results suggested that it is a great burden for primary school teachers with low efficacy in collaboration and managing behaviors to handle students with disabilities alone, and to manage students' disruptive behavior. As mentioned above, Malinen and Savolainen (2016) showed that teacher efficacy in behavior management affected both job satisfaction and burnout, and the findings of this study are in agreement. The reason for this result is because using inclusive instruction represented the least efficacy in primary school. In this context, Chao et al. (2018) revealed that using inclusive instruction represented the least efficacy of the three subscales in primary school. In fact, Sakamoto and Ichikado (2013) revealed that daily educational activities and relationships with parents affect the levels of teacher burnout. Therefore, it is considered that efficacy in collaboration with managing behavior affected emotional distress, but efficiency in using inclusive instructions did not. The results of this study are new findings in that teacher efficacy in collaboration also affected emotional distress. Based on the findings of this study, it is important to focus on efficacy in collaboration and management behavior when formulating support methods for teachers in emotional distress. In other words, it is necessary to provide support methods that enhance teacher efficacy in collaboration and managing behavior among primary school teachers in Japan.

A significant number of previous studies have examined the factors which influence teacher efficacy in collaboration and managing behavior. For example, Peebles and Mendaglio (2014) examined the impact of an inclusion course and field experience on pre-service teachers' efficacy for teaching in inclusive classrooms during their pre-service training and their results indicated that learning about inclusive education and having practical experiences with students with special educational needs produced significant gains in teacher efficacy for inclusive education. In addition, Sokal and Sharma (2014) showed that when teachers' level of confidence in teaching students with disabilities improves, overall teaching efficacy for teaching in inclusive classrooms also improves. Based on these studies, it is considered that pre-service and in-service teachers improve their teacher efficacy by learning about inclusive education and having practical experiences with students with special educational needs. In fact, reports of studies in other countries show that training which enhances teacher efficacy for inclusive education has been developed and has been effective (e.g., Chao et al., 2016; Reina et al., 2019). These training programs included learning about inclusive education and having practical experiences with students with special educational needs. However, such training programs are not widely used in Japan. Therefore, it is to be hoped that these training programs for pre-service and inservice teachers to improve teacher efficacy for collaboration and managing behavior in inclusive classrooms, will spread in Japan.

In this study, we have discussed the effect of attitudes toward inclusive education and teachers' efficacy for inclusive education on teachers' emotional distress in the context of the results of our analysis. These findings can provide useful insights into the issue of emotional distress in primary school teachers. However, a number of limitations of this study need to be acknowledged. First, the results of this study are limited to elementary school teachers. In Japan, junior high and high school teachers do not receive as much training as elementary school teachers on teaching children with disabilities and inclusive education. Therefore, factors affecting teachers' emotional distress may differ for teachers teaching at different levels of the education system. Hence, future research needs to examine the effect of attitudes toward inclusive education and teachers' efficacy for inclusive education among middle school and high school teachers on emotional distress. Second, participants in this study were limited to primary school teachers in the Yamaguchi Prefecture. Thus, future research needs to examine the effect of attitudes toward inclusive education and teachers' efficacy for inclusive education on emotional distress, taking into account 
the gender and work area of the participants. Third, the sample of this study was small. Thus, future research needs to examine the effect of attitudes toward inclusive education and teacher efficacy for inclusive education on teachers' emotional distress among a larger sample of primary school teachers. Fourth, this study was a cross-sectional study. Therefore, it could not fully clarify the causal relationship between teachers' attitudes and teacher efficacy for inclusive education, and emotional distress. Fifth, this study did not fully examine the discrete emotions experienced by teachers. Chen (2016) pointed out that the emotions experienced by teachers were discrete such as sadness, anger, and fear. Therefore, future research needs to examine the relationship between teacher efficacy for inclusive education and these discrete emotions.

\section{DATA AVAILABILITY STATEMENT}

The datasets presented in this article are not readily available because participants agree to participate in the study, provided that the dataset of this study is used only in this study. Therefore, the dataset of this study cannot be used for any other purpose. Requests to access the datasets should be directed to $\mathrm{KN}$, knagase@yamaguchi-pu.ac.jp.

\section{ETHICS STATEMENT}

Ethical review and approval was not required for the study on human participants in accordance with the local legislation

\section{REFERENCES}

Alnahdi, G. H., and Hui, S. K. F. (2019). The Arabic version of the teacher efficacy for inclusive practices (TEIP-AR) scale: a construct validity study. Cogent Educ. 6:1618516. doi: 10.1080/2331186X.2019.1618516

Antonak, R. F., and Larrivee, B. (1995). Psychometric analysis and revision of the opinions relative to mainstreaming scale. Except. Child 62, 139-149. doi: 10.1177/001440299506200204

Avramidis, E., Bayliss, P., and Burden, R. (2000). A survey into mainstream teachers' attitudes towards the inclusion of children with special educational needs in the ordinary school in one local education authority. Educ. Psychol. 20, 191-211. doi: 10.1080/713663717

Beppu, E. (2013). Trends and issues in consultation for teachers of special needs education: a review [In Japanese]. Jpn. J. Spec. Educ. 50, 463-472. doi: 10.6033/ tokkyou. 50.463

Bizer, G. Y., Barden, J. C., and Petty, R. E. (2003). “Attitudes,” in Encyclopedia of Cognitive Science, ed. L. Nadel (London: Nature Publishing Group), 247-253.

Chao, C. N. G., Forlin, C., and Ho, F. C. (2016). Improving teaching self-efficacy for teachers in inclusive classrooms in Hong Kong. Int. J. Inclusive Educ. 20, 1142-1154. doi: 10.1080/13603116.2016.1155663

Chao, C. N. G., Lai, F. T. T., Ji, M., Lo, S. K., and Sin, K. F. (2018). Which inclusive teaching tasks represent the highest level of teacher efficacy in primary and secondary schools? Teach. Teach. Educ. 75, 164-173. doi: 10.1016/j.tate.2018. 06.014

Chen, J. (2016). Understanding teacher emotions: the development of a teacher emotion inventory. Teach. Teach. Educ 55, 68-77. doi: 10.1016/j.tate.2016. 01.001

De Boer, A., Pijl, S. J., and Minnaert, A. (2011). Regular primary schoolteachers' attitudes towards inclusive education: a review of the literature. Int. J. Inclusive Educ. 15, 331-353. doi: 10.1080/13603110903030089 and institutional requirements. The patients/participants provided their written informed consent to participate in this study.

\section{AUTHOR CONTRIBUTIONS}

KN contributed to the design of the study and the data collection, the translation of questionnaire components, analyzed and interpreted the data, drafted the manuscript, approved the final version of the manuscript, and agreed to be accountable to all aspects of this work. KT and KF contributed to the design of the study and the data collection, the translation of questionnaire components, drafted the manuscript, approved the final version of the manuscript, and agreed to be accountable to all aspects of this work. All authors contributed to the article and approved the submitted version.

\section{FUNDING}

This work was supported in part by a Grant-in-Aid for Young Scientists (grant number 20K14165 to KN).

\section{ACKNOWLEDGMENTS}

We express our sincere appreciation to the participants, who generously contributed their time and had the courage to participate in this research.

Doi, Y., and Minowa, M. (2003). Factor structure of the 12-item General Health Questionnaire in the Japanese general adult population. Psychiatry Clin. Neurosci. 57, 379-383. doi: 10.1046/j.1440-1819.2003.01135.x

Goldberg, D. P. (1978). Manual of the General Health Questionnaire. Windsor: NFER-Nelson.

Goldberg, D. P., and Hillier, V. F. (1979). A scaled version of the general health questionnaire. Psychol. Med. 9, 139-145. doi: 10.1017/S0033291700021644

Haq, F. S., and Mundia, L. (2012). Comparison of Brunei preservice student teachers' attitudes to inclusive education and specific disabilities: Implications for teacher education. J. Educ. Res. 105, 366-374. doi: 10.1080/00220671.2011. 627399

Hasegawa-Ohira, M., Matsuzaki, A., Fujimoto, R., and Nomura, S. (2016). Psychophysiological stress evaluation of school teachers using salivary testosterone [In Japanese]. Transact. Jpn. Soc. Kansei Eng. 15, 479-484. doi: 10.5057/jjske. TJSKE-D-16-00003

Higuchi, Y., Inagaki, M., Koyama, T., Kitamura, Y., Sendo, T., Fujimori, M., et al. (2016). A cross-sectional study of psychological distress, burnout, and the associated risk factors in hospital pharmacists in Japan. BMC Public Health 16:534. doi: 10.1186/s12889-016-3208-5

Hopman, J. A. B., Tick, N. T., van der Ende, J., Wubbels, T., Verhulst, F. C., Maras, A., et al. (2018). Special education teachers' relationships with students and selfefficacy moderate associations between classroom-level disruptive behaviors and emotional exhaustion. Teach. Teach. Educ. 75, 21-30. doi: 10.1016/j.tate. 2018.06.004

Ismail, Z., Basheer, I., and Khan, J. H. (2016). Teachers' attitudes towards inclusion of special needs children into primary level mainstream schools in Karachi. Eur. J. Soc. Behav. Sci. 17, 2177-2196. doi: 10.15405/ ejsbs. 195

Kawai, N., and Fujii, A. (2012). A survey of teachers' professional development in special education: The status of licensure of special education teachers [In 
Japanese]. Bull. Graduat. Sch. Educ. Hirosh. Univ. Part 1 Learn. Curric. Dev. 61, 179-187. doi: 10.15027/33971

Malinen, O. P., and Savolainen, H. (2016). The effect of perceived school climate and teacher efficacy in behavior management on job satisfaction and burnout: a longitudinal study. Teach. Teach. Educ 60, 144-152. doi: 10.1016/j.tate.2016. 08.012

Malinen, O. P., Savolainen, H., and Xu, J. (2012). Beijing in-service teachers' selfefficacy and attitudes towards inclusive education. Teach. Teach. Educ. 28, 526-534. doi: 10.1016/j.tate.2011.12.004

Maslach, C., Jackson, S. E., and Leiter, M.P. (eds). (1996). Maslach Burnout Inventory Manual, 3 Edn. Mountain View, CA: CPP Inc.

Minghul, L., Lei, H., Xiaomeng, C., and Potmišilc, M. (2018). Teacher efficacy, work engagement, and social support among Chinese special education school teachers. Front. Psychol. 9:648. doi: 10.3389/fpsyg.2018. 00648

Mori, K., and Tanaka, A. (2011). The present condition of mental health in teachers that engaged in special needs education: from the analysis of GHQ 28 for teachers [In Japanese]. Asian J. Hum. Serv. 1, 112-119.

Mori, K., and Tanaka, A. (2012). Mental health and stressors in teachers that engaged in special needs education: from the analysis of mental health checks for teachers. Bull. Facul. Educ. 80, 183-189.

Murata, Y., and Yamaguchi, M. (2010). "Special needs education system," in Education in Contemporary Japan: System and Content [in Japanese], eds Y. Murata, and M. Yamaguchi (Tokyo: Toshindo), 110-127.

Nakamura, M., and Oka, N. (2007). International trends of inclusive education and special needs education. Education 10, 75-81.

Navarro-Mateu, D., Franco-Ochoa, J., Valero-Moreno, S., and PradoGasco, V. (2019). To be or not to be an inclusive teacher: are empathy and social dominance relevant factors to positive attitudes towards inclusive education? PLoS One 14:e0225993. doi: 10.1371/journal.pone.022 5993

Nishida, J., and Otomo, S. (2010). Influence of exercise and physical activity on the mental health of elementary and junior high school teachers: individual characteristics and experiences with stress [in Japanese]. Jpn. J. Educ. Psychol. 58, 285-297. doi: 10.5926/jjep.58.285

Okamoto, K. (2014). Collaborative methods of instruction and support for students with developmental disabilities who exhibit behavioral problems in school: current trends and issues [in Japanese]. Jpn. J. Spec. Educ. 52, 217-227. doi: $10.6033 /$ tokkyou. 52.217

Özokcu, O. (2018). The relationship between teacher attitude and self-efficacy for inclusive practices in Turkey. J. Educ. Train. Stud. 6, 6-12. doi: 10.11114/jets. v6i33034

Park, M. H., Dimitrov, D. M., Das, A., and Gichuru, M. (2016). The teacher efficacy for inclusive practices (TEIP) scale: dimensionality and factor structure. J. Res. Spec. Educ. Needs 16, 2-12. doi: 10.1111/1471-3802.12047

Peebles, J. L., and Mendaglio, S. (2014). The impact of direct experience on preservice teachers' self-efficacy for teaching in inclusive classrooms. Int. J. Inclusive Educ. 18, 1321-1336. doi: 10.1080/13603116.2014. 899635

Praisner, C. L. (2003). Attitudes of elementary school principals toward the inclusion of students with disabilities. Except. Child. 69, 135-145. doi: 10.1177/ 001440290306900201

Reina, R., Healy, S., Roldán, A., Hemmelmayr, I., and Klavina, A. (2019). Incluye$\mathrm{T}$ : a professional development program to increase the self-efficacy of physical educators towards inclusion. Phys. Educ. Sport Pedagogy 24, 319-331. doi: 10. 1080/17408989.2019.1576863

Sakamoto, Y., and Ichikado, K. (2013). Primary factors leading to burnout among teachers at special needs education schools: exploratory research [in Japanese]. Jpn. J. Spec. Educ. 51, 261-267. doi: 10.6033/tokkyou. 51.261

Salama-Younes, M., Montazeri, A., Ismaill, A., and Roncin, C. (2009). Factor structure and internal consistency of the 12-item General Health Questionnaire (GHQ-12) and the Subjective Vitality Scale (VS), and the relationship between them: a study from France. Health Qual. Life Outcomes 7:22. doi: 10.1186/14777525-7-22
Sharma, U., Loreman, T., and Forlin, C. (2012). Measuring teacher efficacy to implement inclusive practice. J. Res. Spec. Educ. Needs 12, 12-21. doi: 10.1111/ j.1471-3802.2011.01200.x

Sharma, U., Shaukat, S., and Furlonger, B. (2014). Attitudes and self-efficacy of pre-service teachers towards inclusion in Pakistan. J. Res. Spec. Educ. Needs 15, 97-105. doi: 10.1111/1471-3802.12071

Skaalvik, E. M., and Skaalvik, S. (2010). Teacher self-efficacy and teacher burnout: a study of relations. Teach. Teach. Educ. 26, 1059-1069. doi: 10.1016/j.tate.2009. 11.001

Skaalvik, E. M., and Skaalvik, S. (2014). Teacher self-efficacy and perceived autonomy: relations with teacher engagement, job satisfaction, and emotional exhaustion. Psychol. Rep. 114, 68-77. doi: 10.2466/14.02.PR0.114k14w0

Skaalvik, E. M., and Skaalvik, S. (2016). Teacher stress and teacher self-efficacy as predictors of engagement, emotional exhaustion, and motivation to leave the teaching profession. Creat. Edu. 7, 1785-1799. doi: 10.4236/ce.2016.713182

Sokal, L., and Sharma, U. (2014). Canadian in-service teachers' concerns, efficacy, and attitudes about inclusive teaching. Exceptionality Educ. Int. 23, 59-71.

Song, J. (2016). Inclusive education in Japan and Korea: Japanese and Korean teachers' self-efficacy and attitudes towards inclusive education. J. Res. Spec. Educ. Needs 16, 643-648. doi: 10.1111/1471-3802.12324

Stering, M. (2011). General Health Questionnaire-28 (GHQ-28). J. Physiother. 57:259. doi: 10.1016/S1836-9553(11)70060-1

Takahara, R. (2015). Public school teachers' use of sick leave due to mental health: Multilevel structural equation modeling using individual and prefecture-level data [in Japanese]. J. Educ. Psychol. 63, 242-253. doi: 10.5926/jjep.63.242

Takahashi, J., and Matsuzaki, H. (2014). The changes and problems in inclusive education. Bull. Facul. Hum. Dev. Cult. 19, 13-26.

Talmor, R., Reiter, S., and Feigin, N. (2005). Factors relating to regular education teacher burnout in inclusive education. Eur. J. Spec. Needs Educ. 20, 215-229. doi: 10.1080/08856250500055735

Tschannen-Moran, M., and Hoy, A. W. (2001). Teacher efficacy: capturing an elusive construct. Teach. Teach. Educ. 17, 783-805. doi: 10.1016/S0742051X(01)00036-1

Tschannen-Moran, M., Hoy, A. W., and Hoy, W. K. (1998). Teacher efficacy: its meaning and measure. Rev. Educ. Rese. 68, 202-248. doi: 10.3102/ 00346543068002202

UNESCO (1994). The Salamanca Statement and Framework for Action on Special Needs Education. Available online at: http://unesdoc.unesco.org/images/0009/ 000984/098427eo.pdf (accessed January 15, 2020).

Utsumi, Y., and Ando, T. (2017). In-service training program for novice teachers of special needs schools: focus on off-the-job training of a prefectural board of education [in Japanese]. Jpn. J. Disabil. Sci. 41, 91-104. doi: 10.20847/adsj. 41.1_91

Vaz, S., Wilson, N., Falkmer, M., Sim, A., Scott, M., Cordier, R., et al. (2015). Factors associated with primary school teachers' attitudes towards the inclusion of students with disabilities. PLoS One 10:e0137002. doi: 10.1371/journal.pone. 0137002

World Medical Association (2000). Declaration of Helsinki: Ethical Principles for Medical Research Involving Human Subjects. Available online at: https://www. wma.net/wp-content/uploads/2016/11/DoH-Oct2000.pdf. (accessed June 1, 2020).

Yada, A., and Savolainen, H. (2017). Japanese in-service teachers' attitudes toward inclusive education and self-efficacy for inclusive practice. Teach. Teach. Educ. 64, 222-229. doi: 10.1016/j.tate.2017.02.005

Conflict of Interest: The authors declare that the research was conducted in the absence of any commercial or financial relationships that could be construed as a potential conflict of interest.

Copyright (c) 2020 Nagase, Tsunoda and Fujita. This is an open-access article distributed under the terms of the Creative Commons Attribution License (CC BY). The use, distribution or reproduction in other forums is permitted, provided the original author(s) and the copyright owner(s) are credited and that the original publication in this journal is cited, in accordance with accepted academic practice. No use, distribution or reproduction is permitted which does not comply with these terms. 